\title{
The associations of $A C E$ polymorphisms with physical, physiological and skill parameters in adolescents
}

\author{
Colin N Moran ${ }^{1}$, Christos Vassilopoulos ${ }^{1}$, Athanasios Tsiokanos ${ }^{2}$, Athanasios Z Jamurtas ${ }^{2}$, \\ Mark ES Bailey ${ }^{1}$, Hugh E Montgomery ${ }^{3}$, Richard H Wilson ${ }^{1}$ and Yannis P Pitsiladis ${ }^{*}, 1$
}

${ }^{1}$ Institute of Diet, Exercise and Lifestyle (IDEAL), Institute of Biomedical and Life Sciences, University of Glasgow,
Glasgow, UK; ${ }^{2}$ Department of Physical Education and Sport Science, University of Thessaly, Trikala, Greece; ${ }^{3}$ University
College London Centre for Cardiovascular Research, Rayne Institute, University Street, London, UK

Genetic variation in the human Angiotensin I-Converting Enzyme ( $A C E$ ) gene has been associated with many heritable traits, including physical performance. Herein we report the results of a study of several physical, physiological and skill parameters and lifestyle in 1027 teenage Greeks. We show that there is a strong association $(P<0.001)$ between the ACE I/D (insertion/deletion) polymorphism and both handgrip strength and vertical jump in females, homozygotes for the l-allele exhibiting higher performance-related phenotype scores, accounting for up to $4.5 \%$ of the phenotypic variance. The association is best explained by a model in which the $D$-allele is dominant, with the mean phenotypic value in the I/D heterozygotes being close to that of the mean of the DD homozygotes. The association acts across the phenotype distribution in a classical polygenic manner. Other polymorphisms that define major ACE haplotypes in European populations (rs4424958, rs4311) show weaker associations with these performance-related phenotypes than does I/D. Similarly, diplotypes defined by these polymorphisms do not explain significantly larger amounts of the variance than I/D alone. As ACE I/D is the polymorphism most strongly associated with circulating ACE activity in European populations, we propose that the functional allelic differences that influence ACE activity also mediate the associations with the performance-related phenotypes studied here.

European Journal of Human Genetics (2006) 14, 332-339. doi:10.1038/sj.ejhg.5201550; published online 4 January 2006

Keywords: Angiotensin I-converting enzyme; I/D polymorphism; physical performance; haplotype; adolescents; caucasians

\section{Introduction}

Physical performance-related phenotypes are influenced by a combination of genetic and environmental factors, ${ }^{1,2}$ including positive effects of physical activity. The genetic component may involve a number of genes (reviewed in Rankinen $e \mathrm{al}^{3}$ ). Several studies on the influence of genetic variation on physical performance and health-related

*Correspondence: Dr YP Pitsiladis, Institute of Biomedical \& Life Sciences, University of Glasgow, Glasgow G12 8QQ, UK. Tel: +44 141330 3858; Fax: + 44141330 2915; E-mail: Y.Pitsiladis@bio.gla.ac.uk

Received 29 April 2005; revised 10 October 2005; accepted 10 November 2005; published online 4 January 2006 fitness have concentrated on assessing the extent of association between elite athletic status and particular performance genes. There are fewer studies, often with contrasting results, of genetic influences on performancerelated phenotypes in the general population. AngiotensinConverting Enzyme (ACE), a key component of the Renin-Angiotensin System (RAS), converts Angiotensin I to Angiotensin II (a vasopressor) and degrades bradykinin (a vasodilator) and a variety of other active oligopeptides. ${ }^{4}$ Although best known for its function in regulation of blood pressure, recent work has shown that ACE also has a role in diverse cellular processes, including cell growth and survival of nonvascular tissues (reviewed in Danser ${ }^{5}$ ). Local 
RAS systems have been described in several tissues including skeletal muscle (reviewed in Jones and Woods ${ }^{6}$ ) and have been suggested to influence their metabolism.

To date, over 100 polymorphisms have been reported in the $A C E$ gene (http://www.ncbi.nlm.nih.gov/SNP//snp_ref. cgi?locusId $=1636$ ) although most are without obvious functional effect. Historically, work has centred on an insertion-deletion (I/D-allele) polymorphism in intron 16, which is characterised by the presence (I-allele) or absence (D-allele) of a $287 \mathrm{bp}$ Alu repeat sequence. ${ }^{7}$ In Caucasians, the I-allele is associated with lower, and the D-allele with higher, circulating ACE activity; and the I/D polymorphism explains around half of the variance of this activity. ${ }^{7}$ I/D does not, however, explain as large a proportion of this variance in people of African origin, ${ }^{8}$ suggesting that association with ACE activity is mediated through linkage disequilibrium with an (unknown) neighbouring functional quantitative trait locus (QTL). ${ }^{9,10}$ There have been many studies investigating associations between the I/D polymorphism and disease phenotypes or elite physiological phenotypes. Several of these have reported positive associations (reviewed in Snyder et $a l^{11}$ ), whereas others have failed to demonstrate such associations (for example Rankinen et $a l^{12}$ and Sonna et $a l^{13}$ ) - a disparity perhaps partly due to the use of population samples of mixed age, gender and race. ${ }^{14,15}$

The extent to which genes influence performance-related phenotypes varies in response to several factors, including age. For example, twin studies have shown that genes play a larger role in younger age groups, as the environment may be more homogeneous and has had less time to take effect. $^{16}$ Consequently, in these age groups we expect a proportionately higher genetic contribution to phenotypic variation and more readily recognisable interactions between genetic and environmental components. We have studied the effects of variation in $A C E$ and the influence of differences in habitual exercise level on performancerelated phenotypes in a sample of Greek adolescents.

\section{Materials and methods Subjects}

All subjects were of native Greek ethnicity and aged from 11-18 years old. Subjects were drawn from both urban and rural schools surrounding Trikala in central Greece. All pupils from schools agreeing to take part in the research were invited to participate, with fewer than 10\% opting out. All were in good health at the time of testing as assessed by medical questionnaire. The study was approved by the Glasgow University Ethics Committee and local Greek authorities. Written informed consent and parental approval was prospectively obtained for all subjects.

\section{Phenotyping}

Tests were chosen to measure physical, physiological and skill attributes that required little specialist equipment and could be easily carried out in schools. All assessments were carried out by trained individuals following a period of protocol standardisation. Measurements were taken and recorded by two well-trained team members, who were instructed to exchange roles as 'leading' and 'assisting' observer at each session. The role of the 'assisting' observer was to help position the student correctly to the instruments while the 'leading' observer recorded the measurements.

During training, specific instructions were also given with regard to the order of administration of the tasks, area of administration (eg gymnasium or indoor sports hall), type of clothing to be worn, pretest preparation (warm-up), practice trials, instructions to students and exact protocols. At entry to the study, subjects completed a health questionnaire, and another documenting their participation in regular organised physical activity both inside and outside of school. For ethical and practical reasons, we were unable to include an objective measure of puberty. During physical education classes, subjects' physical characteristics (height (m), sitting height (m) and arm span (m)) were measured and used to calculate relative sitting height (sitting height/height) and relative arm span (arm span/ height). Subjects completed a series of tasks designed to measure physical, physiological and skill attributes. These matched those chosen by the Australian Sports Commission for their 'Sport Search'17,18 to allow direct comparison of the results. Briefly, they included sit and reach $(\mathrm{cm})$, handgrip strength ( $\mathrm{kg}$; total for both hands), vertical jump $^{19-22}(\mathrm{~cm})$, basketball throw ${ }^{23,24}(\mathrm{~m})$, throw and catch (catching out of 10 for each hand, giving a total of 20), agility run ${ }^{25}$ (s), $40 \mathrm{~m}$ sprint (s), and the multistage shuttle run test. ${ }^{26,27}$ The multistage shuttle run scores were used to estimate $\dot{\mathrm{V}}_{2} \max$ (weight-corrected maximum rate of oxygen consumption in $\mathrm{mlkg}^{-1} \mathrm{~min}^{-1}$ ) after correction for age as described by Leger et al. ${ }^{28}$ To avoid problems of defining dominant versus nondominant arm for handgrip strength, both arms were tested and the total score used for analysis. For throw and catch, throwing was always performed with the preferred arm, however, both arms were tested for catching and the total score used for the analysis. Reliability and repeatability data for the tests used can be found in Australian sports commission ${ }^{17}$, Leger et $a l^{27}$ and Krombholz. ${ }^{29}$

In summary throw and catch $(r=0.75$, median intratester difference was two catches), basketball throw $(r=0.97$, median intratester difference was $0.10 \mathrm{~m})$, vertical jump $(r=0.88$, median intratester difference was $3 \mathrm{~cm})$, agility run $(r=0.72$, median intratester difference was $0.71 \mathrm{~s}), 40 \mathrm{~m}$ sprint $(r=0.87-0.71$, repeated at up to 2 years) and shuttle run ( $r=0.98$, repeated after 1 week).

In some analyses, we controlled for the effects of physical activity on performance-related phenotypes by assigning individuals scores based on level of physical activity. Habitual physical activity levels in children are inherently difficult to assess ${ }^{30}$ on such a large scale; hence hours of 
organised physical activity only were recorded as a means of differentiating between the active and inactive subjects in this study. Individuals with more than $2 \mathrm{~h}$ of organised physical activity per week were classified as 'active' (and the remainder as 'inactive').

\section{DNA extraction}

Buccal cell samples were obtained by mouthwash or cytology brush (Medical Packaging Corporation, Camarillo, CA, USA) according to the manufacturer's recommendations. DNA was extracted using the PUREGENE ${ }^{\circledR}$ DNA purification kit standard buccal cell protocol (Gentra Systems, Minneapolis, MN, USA) and stored at $-20^{\circ} \mathrm{C}$ in Thermofast rigid semi-skirted 96-well plates (ABgene, Epsom, Surrey, UK). For PCR reactions, 1/100th of each extraction (approximately 20-100 ng) was used as template.

\section{Genotype determination and haplotype inference}

Three polymorphisms in ACE were genotyped (I/D, rs4424958, rs4311; see Supplementary Tables 6-9). These allow classification of $A C E$ genes into four major European haplotypes (H1, H6, H7 and H9) as defined by Rieder et al. ${ }^{31}$ Genotypes and diplotypes (multilocus genotypes defined by haplotype) were determined as previously described. ${ }^{32}$

\section{Data analysis}

Previous studies have shown gender-specific influences of $A C E$ genotype on phenotypic measures, ${ }^{33-35}$ thus data for male and female subjects were analysed separately. Physical ability and physiological parameters also change with age. We chose to account for the effects of age by grouping individuals according to single-year age classes. To maintain comparable numbers among age groups, 11 and 12year-olds were grouped together, and 17 and 18-year-olds were grouped together. Data for each gender and age group were tested separately for normality using the Ryan-Joiner test $^{36}$ and subsequently transformed by logarithmic $\left(\log _{10}\right)$ transformation with the exception of throw and catch for which the arcsine transformation was used. The transformed data were then standardised for age by conversion to $Z$-scores within year groups. All analyses were performed using $z$-scores; however for presentation, z-scores were reverse-transformed to measurements corresponding to the 17-18-year-old group. Habitual exercise levels were controlled for by introducing the activity level score (defined above) into General Linear Model (GLM) ANOVA analyses (using adjusted sums of squares). Differences between genotype/diplotype groups for performance-related phenotypes were assessed using one-way ANOVA. To evaluate the improvement in the associations with the phenotypes produced by assessing diplotypes rather than I/D genotypes, the sum of squares from the I/D genotype ANOVA was subtracted from the sum of squares from the diplotype ANOVA (as were the degrees of freedom) and new $F$ and $P$ values calculated.
The critical value ( $\alpha$-value) of $P$, at which significance was accepted, was corrected for multiple testing (in the ANOVA tests) using the Dunn-Sidak method ${ }^{37}$ as implemented at the SISA ${ }^{38}$ website and taking correlations between phenotypes into account (mean correlation 0.037; see Supplementary Table 5). The corrected $\alpha$-value used was $P<0.003$. Differences judged to be significant were further assessed to investigate the relationship between genotype and phenotype distribution using correlation analysis. Genotypes were assigned 'dummy variable' values according to the genetic model (Additive allelic effects, D-allele dominant or I-allele dominant) being tested. The values assigned to each genotype in the correlation analysis for the Additive genetic model were $0,0.5$ and 1 , representing homozygotes for one allele (DD), heterozygotes (ID) and homozygotes for the other allele (II), respectively; for the completely dominant genetic models, the corresponding values were $0,0,1$ or $0,1,1$, respectively depending on which allele was being tested for dominance. The validity of each genetic model was estimated by expressing $r^{2}$ from the correlation analyses as a percentage of the variance explained by genotype effects in the model-free ANOVAs.

To establish whether the genetic effects are the same in the active and inactive subgroups GLM ANOVAs were used to test for an interaction between genetic model score and activity level score in the total male (or female) groups. Similar tests were used to assess whether stage of pubertal development was a confounding factor in the analysis, by assigning the male and female subjects into 'younger' (age 11-13 years) or 'older' (age 14-18 years) groups.

The influence of genotype on the distribution of phenotypes in the study population was assessed by calculating odds ratios (ORs). For significant genotypephenotype associations (as determined by ANOVA), male and female populations were divided into top, pooledmiddle and bottom quartiles of the phenotype distribution. ORs were calculated ${ }^{39}$ as the likelihood of individuals of a given genotype being in a selected quartile divided by the likelihood of their being in the remaining quartiles. Significance of the ORs was calculated using $2 \times 2 \chi^{2}$ tests and 95\% confidence intervals.

\section{Results \\ Genotyping}

In total, 1198 subjects were recruited, of whom 1084 were included in the analyses. Genotyping was successful in 1027 individuals (543 male, 484 female). Genotype distributions were consistent with Hardy-Weinberg equilibrium and overall allele frequencies were $f_{(D)}=0.57$ and $f_{(I)}=0.43$ for the I/D polymorphism. Other polymorphisms were genotyped to allow haplotype analyses and goodness of fit to Hardy-Weinberg equilibrium and these results are presented in Supplementary Tables 1-4. 


\section{I/D genotype associations with phenotypes}

To control for differences in physical maturity and biases caused by differing psychological factors between genders, males and females were analysed as separate populations. Genotypic associations between the I/D polymorphism and measures of physical, physiological and skill parameter phenotypes were assessed by ANOVA using age-based $z$-values, as described in the methods. Full analyses are presented in the Supplementary Table 6. Similar results were obtained using height-based $z$-values (data not shown). Statistically significant $(P<0.003)$ effects of genotype on phenotype were observed in female subjects but not in male subjects (Table 1). Female subjects with the II genotype had significantly greater handgrip strength and vertical jump scores than individuals with other genotypes (Table 1). Significant differences were established by post hoc $t$-tests. Results for basketball throw, $40 \mathrm{~m}$ sprint and agility run, which also contain components of upper and lower body strength/power but are complicated by additional requirements for skill, are also presented in Table 1 for comparison.

\section{Diplotype associations with phenotypes}

Diplotype associations with the measures of physical, physiological and skill parameter phenotypes were also assessed by ANOVA using age-based $z$-values, as described in the Materials and methods. Full analyses of the additional individual polymorphisms and the diplotypes are presented in Supplementary Tables 7-9. Statistically significant $(P<0.003)$ effects of diplotype on phenotype were observed in female subjects but not in male subjects (Table 1). Female subjects with the H6H6 diplotype (II) had significantly greater handgrip strength and vertical jump scores than individuals with all other diplotypes (Table 1) except H1H9 (DD). Significant differences were established by post hoc $t$ tests. The extra portion of the variance accounted for by using diplotypes instead of I/D genotypes in the analysis was not significant for any phenotype (calculated as described in the Materials and methods). Consequently, subsequent analyses were restricted to the I/D genotype.

\section{Determination of the underlying genetic mechanism for significant associations with the I/D polymorphism}

To explain the pattern of associations observed, three genetic models (Additive allelic effects, I-allele dominant and D-allele dominant) were tested using correlation analysis. In all cases where significant associations were identified by ANOVA, the model in which the phenotypic effects of the D-allele are completely dominant over those of the I-allele (D-allele dominant) explained a larger portion of the genetic variance due to the I/D polymorphism than either of the other models tested: the D-allele dominant model explains 96 and $82 \%$, respectively, of the genetic variance for handgrip strength and vertical jump of total female subjects, the I-allele dominant model 1 and $2 \%$, respectively and the Additive allelic model 38 and $17 \%$, respectively. For each phenotypic parameter more complex genetic models of partial dominance would account for the remaining genetic variance.

\section{Characterisation of $A C E$ I/D genotypic effects on the phenotypic distributions}

The significant effects of I/D genotype on the phenotypes reported above could be due to either a small effect in most individuals, or a large effect in a small number of extreme individuals. For association tests significant by ANOVA, ORs of individuals falling into the lowest or highest quartiles of the population were calculated for each genotype (Table 2). II homozygotes tend to be overrepresented in the high quartile and/or underrepresented in the low quartile groups for the performance-related phenotypes relative to the other genotypes; in contrast, carriers of the dominant D-allele (ID heterozygotes and DD homozygotes) are mostly overrepresented in the low quartile and/or underrepresented in the high quartile groups for the performance phenotypes.

\section{Effect of physical activity level and puberty on I/D genotype associations}

Previous studies have shown effects of training on the association between the I/D polymorphism and cardiovascular phenotypes. ${ }^{40,41}$ To test for possible interactions between physical activity level and genotypic effects on phenotype, GLM ANOVA analysis of the female subject handgrip strength and vertical jump phenotypes (which showed significant genotype effects in the one-way ANOVAs) was performed. The 'best' genetic model (Dallele dominant model, determined above), habitual activity level and the interaction between the two were investigated. No correction for multiple testing was employed as the source of the established associations was being investigated. No significant interactions were observed (Table 3) between the genetic model and the physical activity level for any of the phenotypes significant by one-way ANOVA (see Table 1). For illustrative purposes, one-way ANOVA analyses were also performed on the activity-based subgroups separately (Supplementary Tables 6-9). The lack of effect of physical activity level on the genotypic associations (one-way ANOVA) is illustrated for handgrip strength in Figure 1, which shows that female subjects with an II genotype tend to have higher values for this phenotype than female subjects with other genotypes, a pattern apparent in both active and inactive subgroups. In addition, the figure illustrates that active female subjects have significantly greater handgrip strength than their inactive counterparts (tested using General Linear Model statistics, see Table 3).

We wished to test whether puberty was a confounding factor in this study. However, as for ethical and practical 
Table 1 Associations between I/D genotype and physical, physiological and skill parameter phenotypes in female subjects and male subjects

\begin{tabular}{|c|c|c|c|c|c|}
\hline & Handgrip strength & Basketball throw & Vertical jump & $40 \mathrm{~m}$ sprint & Agility run \\
\hline \multicolumn{6}{|l|}{ Total Females } \\
\hline \multirow[t]{3}{*}{ I/D genotype } & $\begin{array}{l}I I=53.9(51.8-56.0) \\
I D=484(472-495)\end{array}$ & $\begin{array}{l}I I=4.7(4.5-4.8) \\
I D=4.4(4.4-4.5)\end{array}$ & $\begin{aligned} I I & =32.8(31.7-33.9)\end{aligned}$ & $I I=7.3(7.2-7.4)$ & $\begin{array}{ll}I I & =21.1(20.8-21.4)\end{array}$ \\
\hline & $\begin{aligned} 1 \mathrm{D} & =48.4(47.2-49.3) \\
\mathrm{DD} & =49.2(47.6-50.9)\end{aligned}$ & $\begin{aligned} I D & =4.4(4.4-4.3) \\
D D & =4.5(4.4-4.7)\end{aligned}$ & $\begin{aligned} \mathrm{IV} & =30.0(29.3-30.6) \\
\mathrm{DD} & =31.0(30.3-31.6)\end{aligned}$ & $\begin{array}{l}D D=7.6(7.3-7.6) \\
D D=7.4(7.3-7.5)\end{array}$ & $\mathrm{DD}=21.2(20.9-21.5)$ \\
\hline & $\begin{aligned} & V= 4 \%, N=479 \\
& P<0.001\end{aligned}$ & $\begin{aligned} & V= 1.9 \%, N=480 \\
& P=0.011\end{aligned}$ & $V=4.5 \%, N=481$ & $\begin{array}{c}V=2.4 \%, N=463 \\
P=0.004\end{array}$ & $\begin{array}{c}V=0.4 \%, N=475, \\
P=0.359\end{array}$ \\
\hline \multirow[t]{8}{*}{ Diplotype } & $\mathrm{H} 6 \mathrm{H} 6=54.2(52.0-56.5)$ & $\mathrm{H} 6 \mathrm{H} 6=4.7(4.5-4.9)$ & $\mathrm{H} 6 \mathrm{H} 6=33.3(32.1-34.4)$ & $H 6 H 6=7.3(7.2-7.4)$ & $\mathrm{H} 6 \mathrm{H} 6=21.1(20.8-21.4)$ \\
\hline & $\mathrm{H} 1 \mathrm{H} 6=48.6(47.2-50.0)$ & $\mathrm{H} 1 \mathrm{H} 6=4.4(4.3-4.5)$ & $\mathrm{H} 1 \mathrm{H} 6=30.0(29.3-30.7)$ & $H 1 H 6=7.6(7.5-7.7)$ & $\mathrm{H} 1 \mathrm{H} 6=21.4(21.1-21.6)$ \\
\hline & $\begin{array}{l}\mathrm{H} 6 \mathrm{H7}=48.3(46.1-50.6) \\
\mathrm{H} 6 \mathrm{H9}=46.0(421-502\end{array}$ & $\begin{array}{l}\mathrm{H} 6 \mathrm{H7}=4.5(4.3-4.7) \\
\mathrm{H} 6 \mathrm{H}=4.4(41-4.7)\end{array}$ & $\begin{array}{l}\mathrm{H} 6 \mathrm{H7}=30.2(29.0-31.4) \\
\mathrm{H} 6 \mathrm{H}=29.6(27 .-31.7\end{array}$ & $\begin{array}{l}H 6 H 7=7.5(7.3-7.6) \\
H 6 H 9=76(73-7.9)\end{array}$ & $\begin{array}{l}\mathrm{H} 6 \mathrm{HZ}=21.4(20.9-21.9) \\
\mathrm{H} 6 \mathrm{HO}=21.2(206-21.9)\end{array}$ \\
\hline & $\mathrm{H} 1 \mathrm{H} 1=49.8(47.4-52.4)$ & $\mathrm{H} 1 \mathrm{H} 1=4.5(4.4-4.7)$ & $\mathrm{H} 1 \mathrm{H} 1=31.1(30.1-32.1)$ & $H 1 H 1=7.5(7.3-7.6)$ & $\mathrm{H} 1 \mathrm{H} 1=21.2(20.8-21.6)$ \\
\hline & $\mathrm{H} 1 \mathrm{H7}=48.5(45.7-51.4)$ & $\mathrm{H} 1 \mathrm{H7}=4.5(4.4-4.7)$ & $\mathrm{H} 1 \mathrm{H7}=30.3(29.1-31.5)$ & $H 1 H 7=7.5(7.3-7.7)$ & $\mathrm{H} 1 \mathrm{H} 7=21.6(21.0-22.2)$ \\
\hline & $\mathrm{H} 1 \mathrm{H} 9=50.1(45.3-55.5)$ & $\mathrm{H} 1 \mathrm{H} 9=4.6(4.3-5.0)$ & $\mathrm{H} 1 \mathrm{H} 9=31.6(29.6-33.7)$ & $H 1 H 9=7.2(7.0-7.5)$ & $\mathrm{H} 1 \mathrm{H} 9=20.6(19.9-21.4)$ \\
\hline & Rare $=47.3(42.4-52.8)$ & Rare $=4.6(4.3-5.0)$ & Rare $=31.9(30.0-34.0)$ & Rare $=7.3(6.9-7.7)$ & Rare $=20.8(20.3-21.3)$ \\
\hline & $V=5.1 \%, N=448$ & $V=2.2 \%, N=448$ & $V=6.4 \%, N=449$ & $V=4.4 \%, N=434$ & $V=1.7 \%, N=444$ \\
\hline \multirow{5}{*}{$\begin{array}{l}\text { Total males } \\
\text { I/D genotype }\end{array}$} & $P=0.002$ & $P=0.189$ & $P<0.001$ & $P=0.008$ & $P=0.369$ \\
\hline & II $=78.4(75.6-81.2)$ & $I I=6.9(6.7-7.1)$ & $I I=43.6(42.3-45.1)$ & $I I=6.0(5.9-6.1)$ & $I I=19.0(18.7-19.2)$ \\
\hline & $\mathrm{ID}=79.5(77.4-81.6)$ & $\mathrm{ID}=6.7(6.6-6.9)$ & $\mathrm{ID}=44.4(43.5-45.3)$ & $\mathrm{ID}=6.0(6.0-6.1)$ & $\mathrm{ID}=18.9(18.8-19.1)$ \\
\hline & $\mathrm{DD}=81.0(79.2-83.5)$ & $\mathrm{DD}=6.9(6.7-7.1)$ & $\mathrm{DD}=45.0(44.0-46.0)$ & $\mathrm{DD}=6.0(5.9-6.0)$ & $\mathrm{DD}=18.9(18.7-19.0)$ \\
\hline & $\begin{array}{c}V=0.5 \%, N=535 \\
P=0.267\end{array}$ & $\begin{array}{c}V=0.7 \%, N=535 \\
P=0.153\end{array}$ & $\begin{array}{l}V=0.5 \%, N=534, \\
P=0.285\end{array}$ & $V=0.1 \%, N=521$ & $\begin{array}{l}V=0.1 \%, N=527, \\
P=0,717\end{array}$ \\
\hline \multirow[t]{9}{*}{ Diplotype } & $\mathrm{H} 6 \mathrm{H} 6=78.7(75.7-81.7)$ & $\mathrm{H} 6 \mathrm{H} 6=6.9(6.7-7.1)$ & $\mathrm{H} 6 \mathrm{H} 6=43.7(42.2-45.2)$ & $\mathrm{H} 6 \mathrm{H} 6=6.0(5.9-6.1)$ & $\mathrm{H} 6 \mathrm{H} 6=19.0(18.8-19.3)$ \\
\hline & $\mathrm{H} 1 \mathrm{H} 6=79.3(76.7-81.9)$ & $\mathrm{H} 1 \mathrm{H} 6=6.7(6.6-6.9)$ & $\mathrm{H} 1 \mathrm{H} 6=44.4(43.3-45.6)$ & $\mathrm{H} 1 \mathrm{H} 6=6.0(6.0-6.1)$ & $\mathrm{H} 1 \mathrm{H} 6=19.0(18.7-19.2)$ \\
\hline & $\mathrm{H} 6 \mathrm{H7}=80.9(76.4-85.6)$ & $\mathrm{H} 6 \mathrm{H7}=6.8(6.5-7.1)$ & $\mathrm{H} 6 \mathrm{H} 7=44.3(42.6-46.1)$ & $\mathrm{H} 6 \mathrm{H7}=6.1(5.9-6.2)$ & $\mathrm{H} 6 \mathrm{H7}=18.9(18.6-19.2)$ \\
\hline & $\mathrm{H} 6 \mathrm{H} 9=77.1(70.1-84.7)$ & $\mathrm{H} 6 \mathrm{H} 9=6.2(5.8-6.6)$ & $\mathrm{H} 6 \mathrm{H} 9=43.7(40.6-47.1)$ & $\mathrm{H} 6 \mathrm{H} 9=5.9(5.7-6.2)$ & $\mathrm{H} 6 \mathrm{H} 9=18.8(18.2-19.3)$ \\
\hline & $\mathrm{H} 1 \mathrm{H} 1=80.7(77.8-83.7)$ & $\mathrm{H} 1 \mathrm{H} 1=6.9(6.7-7.1)$ & $\mathrm{H} 1 \mathrm{H} 1=45.4(44.1-46.8)$ & $\mathrm{H} 1 \mathrm{H} 1=5.9(5.9-6.0)$ & $\mathrm{H} 1 \mathrm{H} 1=18.7(18.5-18.9)$ \\
\hline & $\mathrm{H} 1 \mathrm{H7}=82.4(78.2-86.9)$ & $\mathrm{H} 1 \mathrm{H7}=6.8(6.4-7.3)$ & $\mathrm{H} 1 \mathrm{H7}=43.9(41.9-45.9)$ & $\mathrm{H} 1 \mathrm{H7}=6.1(5.9-6.2)$ & $\mathrm{H} 1 \mathrm{H7}=19.1(18.8-19.6)$ \\
\hline & $\mathrm{H} 1 \mathrm{H} 9=81.8(76.4-87.4)$ & $\mathrm{H} 1 \mathrm{H} 9=6.7(6.4-7.0)$ & $\begin{array}{l}\mathrm{H} 1 \mathrm{H} 9=45.4(42.9-47.9) \\
\mathrm{Rare}=4376(40.4-47.4\end{array}$ & $\begin{aligned} \mathrm{H} 1 \mathrm{H} 9=6.0(5.8-6.2) \\
\text { Rare }=59(5-6.2)\end{aligned}$ & $\begin{aligned} \mathrm{H} 1 \mathrm{H} 9 & =18.8(18.4-19.2) \\
\mathrm{Rare} & =188(182-193\end{aligned}$ \\
\hline & $\begin{array}{l}\text { Rare }=86.7(79.4-94.6) \\
V=1.2 \%, N=500\end{array}$ & $\begin{array}{l}\text { Rare }=7.0 \quad(6.3-7.7) \\
V=1.9 \%, N=500\end{array}$ & $\begin{array}{c}\text { Rare }=43.76(40.4-47.4) \\
V=0.8 \% N=499\end{array}$ & $\begin{array}{l}\text { Rare }=5.9(5.7-6.2) \\
V=1 \%, N=486\end{array}$ & $\begin{array}{c}\text { Rare }=18.8(18.2-19.3) \\
V=1.1 \%, N=492\end{array}$ \\
\hline & $P=0.518$ & $P=0.225$ & $P=0.794$ & $P=0.669$ & $P=0.584$ \\
\hline
\end{tabular}

Summary of phenotypes significant by ANOVA and related phenotypes. For each test means and $95 \%$ confidence interval for the mean are shown for each genotype/diplotype as well as percentage variance explained in ANOVA $(V)$, number of individuals $(N)$ and probability $(P)$. Rare represents $\mathrm{H7H7}, \mathrm{H7H} 9$ and $\mathrm{H} 9 \mathrm{H} 9$. Tests significant after a Sidak correction $(P<0.003)$ are shown in bold. Tests with $P<0.05$ are shown in italics. Note that smaller values for $40 \mathrm{~m}$ sprint and agility run are faster. $\mathrm{H} 6$ carries the I-allele, whereas $\mathrm{H} 1, \mathrm{H} 7$ and $\mathrm{H} 9$ all carry the Dallele. Full analyses are shown in Supplementary Tables 6-9. 
reasons it was not possible to assess stage of pubertal development directly, age was used as a surrogate. The population was split into younger and older subgroups, as described in the Materials and methods, and the interaction between the (D-dominant) genetic model and puberty group assessed by GLM ANOVA. A significant interaction component would indicate different genotype-phenotype relationships pre- and post-pubertally. No significant interactions were observed between genetic model and these age groups (Table 3) suggesting that female subject pubertal status is not a confounding variable in these analyses.

\section{Discussion}

Variation within the $A C E$ gene was significantly associated with two of the physical, physiological and skill phenotypes measured in this cohort of Greek adolescents. These associations were found only in female subjects and were not significantly influenced by physical activity level or

Table 2 ACE I/D genotype odds ratios for phenotypes significant by ANOVA (Table)

Total females

\begin{tabular}{|c|c|c|c|}
\hline genotype & Phenotype & Low quartile & High quartile \\
\hline \multirow[t]{2}{*}{11} & Hand & $0.28(0.1$ & $2.42^{* *}$ \\
\hline & $\mathrm{Ve}$ & $0.50(0.2$ & $2.21^{*}($ \\
\hline \multirow[t]{2}{*}{ ID } & Hand grip & $1.69(1.12-2.55)$ & $0.62(0.4$ \\
\hline & Vert & $1.88^{*}(1.26-2.79)$ & $0.69(0$ \\
\hline \multirow[t]{2}{*}{ DD } & Hand grip & $1.05(0.68-1.62)$ & $0.91(0.58-1.42)$ \\
\hline & Vertical jump & $0.73(0.47-1.22)$ & $0.86(0.53-1.37)$ \\
\hline
\end{tabular}

$95 \%$ confidence intervals are given in parentheses. Probability $(P)$ $<0.05$ for tests shown in bold, * indicates $P \leqslant 0.01$, ** indicates $P \leqslant 0.001$. Low quartile means less strong (handgrip strength) and smaller jump (vertical jump). High quartile indicates the converse.

Table 3 Effect of age and activity on genotype-phenotype associations

\begin{tabular}{lcrrrr}
\hline & \multicolumn{2}{c}{ Handgrip } & \multicolumn{2}{c}{ Vertical jump } \\
Total females & $V(\%)$ & $P$ & $V(\%)$ & \multicolumn{1}{c}{$P$} \\
\hline Active versus inactive $(N=273$ & versus & $205)$ & & \\
D Dominant Model Scores & 3.8 & $<\mathbf{0 . 0 0 1}$ & 3.7 & $<\mathbf{0 . 0 0 1}$ \\
Activity Level Scores & $\mathbf{1 . 5}$ & $\mathbf{0 . 0 0 7}$ & $\mathbf{1 . 5}$ & $\mathbf{0 . 0 0 6}$ \\
Interaction & 0.1 & 0.414 & $<0.1$ & 0.984 \\
& & & & \\
Younger versus older (N=169 versus & $311)$ & & \\
D Dominant Model Scores & $\mathbf{2 . 8}$ & $<\mathbf{0 . 0 0 1}$ & $\mathbf{3 . 4}$ & $<\mathbf{0 . 0 0 1}$ \\
Age Group Scores & $\mathbf{1 . 3}$ & $\mathbf{0 . 0 1 1}$ & $<0.1$ & 0.986 \\
Interaction & 0.2 & 0.306 & 0.2 & 0.290
\end{tabular}

Summary of GLM ANOVA analysis for phenotypes significant by oneway ANOVA (see Table 1), analysing the interaction between the Ddominant genetic model and physical activity-based, or age-based, assignments in female subjects. For each test, the percentage variance $(V)$ (and its probability $(P)$ ) explained by each element of the model is given. Specifically these are genotype alone, activity level (or age group) alone and the interaction between genotype and activity level (or age group). pubertal status. Homozygotes for the I-allele were associated with better performance in two of the tests, handgrip and vertical jump, indicating a recessive action of the I-allele. Based on the ORs, these associations acted across the entire phenotypic distribution in a classical polygenic manner.

Handgrip strength and vertical jump were strongly associated with the I/D polymorphism in female subjects. We interpret these activities as having many different components including strength/power (upper limb and lower body, respectively) and skill. Single genetic polymorphisms are likely to affect individual components of complex phenotypes. How easily identified these effects are will depend on the relative importance of the given component to the specific performance-related test. Two of the other tests used, Basketball throw and $40 \mathrm{~m}$ sprint, also have respective upper and lower body strength/power-related components, but require larger elements of skill and thus relate to strength/power more indirectly. Both showed nominal associations with genotype in the same subjects. We interpret this as indicating that the significant associations observed relate more to the strength/power component of the phenotypes investigated than to other components. In all cases, the II homozygotes performed best.

Haplotype-based methods have been advocated to better assess complex genetic influences on phenotype (for example Akey et $a l^{42}$ ). However, the genotyping of additional ACE polymorphisms (rs4424958 and rs4311) that help define four major European haplotypes (H1, H6, H7 and H9; Rieder et $a^{31}$; see Table 1 and Supplementary Tables 6-9) shows that the haplotypes explained no significantly greater proportion of the phenotypic variance than the I/D polymorphism analysed alone (based on the increase in the sum of squares; see Materials and methods; note that the percentage of variance explained depends on the degrees of freedom and inevitably goes up when the data are split into more groups). This suggests that the majority of the genetic effects are accounted for either by

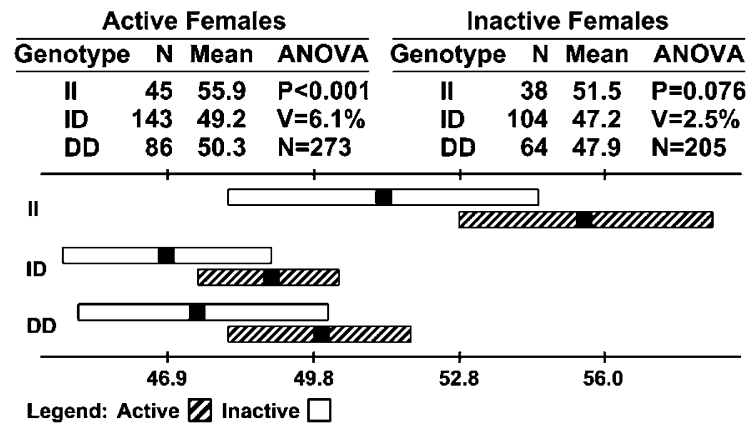

Figure 1 I/D genotypic effect on handgrip strength of active and inactive females. The values given for means are back transformed to equivalent 17-18-year-old female performance values (in $\mathrm{kg}$ ). $P=$ probability, $V=$ observed variance explained, $N=$ number within group. Black squares represent genotype means; boxes represent $95 \%$ confidence intervals of means. 
the I/D polymorphism or a variant in strong linkage disequilibrium with it. In other studies of $A C E$ variation, the I/D polymorphism shows a stronger association with levels of circulating ACE activity in Caucasians than do other $A C E$ variants. ${ }^{43}$ We conclude that, in our studies, the genotypic effects on these diverse physical, physiological and skill parameter phenotypes may be mediated by variation in the levels of ACE activity associated with the ACE I/D polymorphism.

The significant associations (ORs) in both tails of the phenotype distributions rule out explanations involving only a few extreme individuals at one end of the distributions and suggest that the I/D associations with phenotypes act throughout the whole phenotypic range. This is consistent with a classical polygenic effect, where the genotype has a small phenotypic effect on all individuals. The significant phenotypic differences between genotypes were best explained by a D-allele dominant (I-allele recessive) genetic model, as demonstrated for handgrip strength in Figure 1. Dominant genetic effects on phenotype are mediated through a number of mechanisms, most commonly through alteration of active protein levels beyond threshold values or effects on multimeric proteins. Given the association of the I/D polymorphism with ACE levels in Caucasians $^{7,44}$ and the fact that it acts as a monomer it is likely that the higher level of ACE activity associated with ID heterozygotes and DD homozygotes is above a threshold; ACE activity in II homozygotes on the other hand may tend to be below this threshold and hence contribute to the positive effects on performance phenotypes. Given its role in the processing of Angiotensin I, bradykinin and other oligopeptides, ${ }^{4}$ differences in local $\mathrm{ACE}^{6}$ activity may result in alterations to the physiology of skeletal muscle by a variety of possible mechanisms. However, it is important to note that these effects may differ between populations of different gender, age and environment.

ANOVA analyses of the active and inactive female populations (Supplementary Tables 6-9) suggested that the observed effects might be influenced by physical activity. However, further analysis by GLM ANOVA, under the D-dominant genetic model did not provide evidence for an interaction effect between genotype and activity, suggesting that in fact there are no significant differences between the genotype-phenotype relationships of these two subgroups of the population (Table 3). Nor were any significant interactions observed between genotypic effects under this model and age when the latter was modelled as 'younger' versus 'older' subgroups. This suggests that puberty is unlikely to be a significant factor in modifying the genotype-phenotype associations reported here.

Circulating ACE activity has been shown to be reduced in women undergoing hormone replacement therapy with oestrogen and progesterone. ${ }^{45}$ These hormones will be found naturally in the adolescent girls in the current cohort and may explain the gender-specific differences observed. Such a mechanism is postulated by Fischer et al. ${ }^{46}$ In the absence of these hormones, as is the case in male subjects, ACE activity may be above the required threshold regardless of I/D genotype. Further investigations are required to elucidate the molecular mechanisms explaining the involvement of the ACE gene in human performance.

Most previous studies have concentrated on elite athletes, linking the $A C E$ I-allele to endurance performance ${ }^{47}$ and the D-allele to muscle strength and power-oriented performance. ${ }^{48}$ However, a previous study by Cam et al ${ }^{49}$ on the influence of $A C E$ genotype on performance in a male population associated the DD genotype with endurance performance. Our findings that the I-allele is associated with phenotypes related more to strength than to endurance is consistent with this latter study. Our findings indicate a more complex role for the ACE gene in human physical performance than previously described. The I-allele was associated, in a recessive manner, with improved physical, physiological and skill parameter values in female subjects from a large representative sample of young individuals. This association was not significantly modified by participation in organised physical activity. The association of the Iallele with power-related performance is apparently in conflict with several previous studies. However, these studies were carried out using highly selected elite male cohorts, or by analysing individual responses to a highly structured training program in adults, and may not be directly comparable. These studies were relatively small and had an inherently lower power to detect small effects such as those observed in our study. Our results demonstrate that the $A C E$ gene has a modest influence on physical performance in the general population. Future work should concentrate on the mechanisms by which ACE influences performance-related phenotypes.

\section{Acknowledgements}

This research was supported in part by a Grant from the MRC/BBSRC associate programme in human nutrition research (\#17/D17566). The authors have no conflicts of interest to declare. The cooperation of all schools and subjects is greatly appreciated.

\section{References}

1 Heck AL, Barroso CS, Callie ME, Bray MS: Gene-nutrition interaction in human performance and exercise response. Nutrition 2004; 20: 598-602.

2 Philippaerts RM, Lefevre J, Delvaux K et al: Associations between daily physical activity and physical fitness in Flemish males: a cross-sectional analysis. Am J Hum Biol 1999; 11: 587-597.

3 Rankinen T, Perusse L, Rauramaa R, Rivera MA, Wolfarth B, Bouchard C: The human gene map for performance and healthrelated fitness phenotypes: the 2003 update. Med Sci Sports Exerc 2004; 36: 1451-1469.

4 Skidgel RA, Erdos EG: Angiotensin converting enzyme (ACE) and neprilysin hydrolyze neuropeptides: a brief history, the beginning and follow-ups to early studies. Peptides 2004; 25: 521-525. 
5 Danser AHJ: Local renin-angiotensin systems: the unanswered questions. Int J Biochem Cell Biol 2003; 35: 759-768.

6 Jones A, Woods DR: Skeletal muscle RAS and exercise performance. Int J Biochem Cell Biol 2003; 35: 855-866.

7 Rigat B, Hubert C, Alhencgelas F, Cambien F, Corvol P, Soubrier F: An insertion deletion polymorphism in the Angiotensin Iconverting enzyme gene accounting for half the variance of serum enzyme levels. J Clin Invest 1990; 86: 1343-1346.

8 Bloem LJ, Manatunga AK, Pratt JH: Racial difference in the relationship of an angiotensin I- converting enzyme gene polymorphism to serum angiotensin I- converting enzyme activity. Hypertension 1996; 27: 62-66.

9 Zhu XF, McKenzie CA, Forrester T et al: Localization of a small genomic region associated with elevated ACE. Am J Hum Genet 2000; 67: 1144-1153.

10 Scott RA, Moran C, Wilson RH et al: No association between Angiotensin Converting Enzyme (ACE) gene variation and endurance athlete status in Kenyans. Comparat Biochem Physiol 2005; 141: 169-175.

11 Snyder EE, Walts B, Perusse L et al: The human obesity gene map: the 2003 update. Obes Res 2004; 12: 369-439.

12 Rankinen T, Wolfarth B, Simoneau JA et al: No association between the angiotensin-converting enzyme ID polymorphism and elite endurance athlete status. J Appl Physiol 2000; 88: 1571-1575.

13 Sonna LA, Sharp MA, Knapik JJ et al: Angiotensin-converting enzyme genotype and physical performance during US Army basic training. J Appl Physiol 2001; 91: 1355-1363.

14 Woods DR, Brull D, Montgomery HE: Endurance and the ACE I/D polymorphism. Sci Prog 2000; 83: 317-336.

15 Montgomery H, Dhamrait S: ACE genotype and performance. J Appl Physiol 2002; 92: 1774-1775.

16 Maes HH, Beunen GP, Vlietinck RF et al: Inheritance of physical fitness in 10-yr-old twins and their parents. Med Sci Sports Exerc 1996; 28: 1479-1491.

17 Australian Sports Commission: Sport Search - The Search is Over. Canberra, Australia: Australian Sports Commission, 1993.

18 Tomkinson GR, Olds TS, Gulbin J: Secular trends in physical performance of Australian children. J Sports Med Phys Fit 2003; 43: $90-98$.

19 Draper JA, Minikin B, Telford R: Test Methods Manual. Canberra: National Sports Research Centre, Australian Sports Commission, 1991.

20 Ostyn M, Simons J, Beunen G, Renson R, Van Gerven D: Somatic and Motor Development of Belgian Secondary Schoolboys: Norms and Standards. Leuven: Leuven University Press, 1980.

21 Simons J, Beunen GP, Renson R, Claessens ALM, Van Reusel B, Lefevre JAV: Growth and Fitness of Flemish Girls: The Leuven Growth Study. Champaign, Illinois, 1990.

22 Bloomfield J, Blanksby BA, Elliot BC, Ackland TR, Morton AR: University of Western Australia Growth and Development Study. University of Western Australia: Department of Human Movement Studies, 1983

23 Gillespie J, Keenum S: A validity and reliability-analysis of the seated shot put as a test of power. J Hum Movement Stud 1987; 13: 97-105.

24 Viitasalo JT: Evaluation of explosive strength for young and adult athletes. Res Q Exerc Sport 1988; 59: 9-13.

25 Adam C, Klissouras V, Ravassolo M: Eurofit. Handbook for the Eurofit test of Physical Fitness. Council of Europe. Committee for the Development of Sport: Rome, 1988.

26 Leger L, Gadoury C: Validity of the 20-M shuttle run test with 1-min stages to predict $\dot{\mathrm{V}}_{2}$ max in adults. Can J Sport Sci 1989; 14: $21-26$.

27 Leger LA, Lambert J: A maximal multistage 20-M shuttle run test to predict $\mathrm{VO}_{2}$ Max. Eur J Appl Physiol Occup Physiol 1982; 49: 1-12.

28 Leger LA, Mercier D, Gadoury C, Lambert J: The multistage 20 metre shuttle run test for aerobic fitness. J Sports Sci 1988; 6: 93-101.
29 Krombholz H: Results in regard to the 'International Standard Fitness Test' (ISFT) - reliability and norms for primary school children. Int J Phys Edu 1986; 23: 8-17.

30 Washburn RA, Montoye HJ: The assessment of physical-activity by questionnaire. Am J Epidemiol 1986; 123: 563-576.

31 Rieder MJ, Taylor SL, Clark AG, Nickerson DA: Sequence variation in the human angiotensin converting enzyme. Nature Genet 1999; 22: $59-62$.

32 Moran CN, Vassilopoulos C, Tsiokanos A et al: Effects of interaction between ACE polymorphisms and lifestyle on obesity-related phenotypes in adolescent Greeks. Obes Res 2005; 13: $1499-1504$

33 O'Donnell CJ, Lindpaintner K, Larson MG et al: Evidence for association and genetic linkage of the angiotensin-converting enzyme locus with hypertension and blood pressure in men but not women in the Framingham Heart Study. Circulation 1998; 97: $1766-1772$.

34 Crawford F, Abdullah L, Schinka J et al: Gender-specific association of the angiotensin converting enzyme gene with Alzheimer's disease. Neurosci Lett 2000; 280: 215-219.

35 Orlowska-Baranowska E, Placha G, Gaciong Z et al: Influence of ACE I/D genotypes on left ventricular hypertrophy in aortic stenosis: gender-related differences. J Heart Valve Dis 2004; 13: 574-581.

36 Ryan Jr TA, Joiner BL: Normal Probability Plots and Tests for Normality. PA, USA: Statistics Department, The Pennsylvania State University, 1976.

37 Sokal RR, Rohlf FJ: Biometry: The Principles and Practice of Statistics in Biological Research. New York: W.H. Freeman and Company, 1995.

38 Uitenbroek DG: SISA Binomial; in Uitenbroek. DG (ed): Southampton, 1997, http://home.clara.net/sisa/binomial.htm. Accessed April 1, 2005.

39 Armitage P, Berry G: Statistical Methods in Medical Research. Oxford: Blackwell Scientific Publications, 1994.

40 Woods D, Onambele G, Woledge R et al: Angiotensin-I converting enzyme genotype-dependent benefit from hormone replacement therapy in isometric muscle strength and bone mineral density. J Clin Endocrinol Metab 2001; 86: 2200-2204.

41 Montgomery HE, Marshall R, Hemingway $\mathrm{H}$ et al: Human gene for physical performance. Nature 1998; 393: 221-222.

42 Akey J, Jin L, Xiong MM: Haplotypes versus single marker linkage disequilibrium tests: what do we gain? Eur J Hum Genet 2001; 9: 291-300.

43 Soubrier F, Martin S, Alonso A et al: High-resolution genetic mapping of the ACE-linked QTL influencing circulating ACE activity. Eur J Hum Genet 2002; 10: 553-561.

44 Danser AHJ, Schalekamp M, Bax WA et al: Angiotensin-converting enzyme in the human heart - effect of the deletion insertion polymorphism. Circulation 1995; 92: 1387-1388.

45 Proudler AJ, Ahmed AIH, Crook D, Fogelman I, Rymer JM, Stevenson JC: Hormone replacement therapy and serum angiotensin converting-enzyme activity in postmenopausal women. Lancet 1995; 346: 89-90.

46 Fischer M, Baessler A, Schunkert H: Renin angiotensin system and gender differences in the cardiovascular system. Cardiovasc Res 2002; 53: 672-677.

47 Myerson S, Hemingway H, Budget R, Martin J, Humphries S, Montgomery $\mathrm{H}$ : Human angiotensin I-converting enzyme gene and endurance performance. J Appl Physiol 1999; 87: $1313-1316$.

48 Nazarov IB, Woods DR, Montgomery HE et al: The angiotensin converting enzyme I/D polymorphism in Russian athletes. Eur J Hum Genet 2001; 9: 797-801.

49 Cam FS, Colakoglu M, Sekuri C, Colakoglu S, Sahan C, Berdeli A: Association between the ACE I/D gene polymorphism and physical performance in a homogeneous non-elite cohort. Can J Appl Physiol-Rev Can Physiol Appl 2005; 30: 74-86.

Supplementary Information accompanies the paper on European Journal of Human Genetics website (http://www.nature.com/ejhg) 